\title{
APRESENTAÇÃO \\ ESTUDOS DA TRADUÇÃO E DA INTERPRETAÇÃO DE LÍNGUAS DE SINAIS: ATUALIDADES, PERSPECTIVAS E DESAFIOS
}

O primeiro número da Cadernos de Tradução dedicado às pesquisas sobre a tradução e a interpretação de línguas de sinais foi organizado por Ronice Müller de Quadros e publicado em outubro de 2010 com o título: "Tradução e Interpretação de Línguas de Sinais" (v. 2, n. 26). No início da apresentação, desse volume especial, lemos o seguinte: "como vocês vão perceber por meio da leitura dos artigos aqui organizados, as pesquisas sobre tradução e interpretação de línguas de sinais são muito recentes, especialmente no Brasil [...] os Cadernos de Tradução vem coroar a afiliação destes campos aos Estudos da Tradução" (Quadros 9). De fato, esse volume, o primeiro em nível nacional inteiramente composto por artigos com foco na tradução ou na interpretação envolvendo línguas de sinais, marca a trajetória inicial do que ficou conhecido, nos anos seguintes, como os "Estudos da Tradução e da Interpretação de Línguas de Sinais (ETILS)".

Desde esse volume seminal, passaram-se mais de onze anos, os quais foram marcados pela profusão de pesquisas sobre a tradução, a interpretação e a guia-interpretação de/entre/para línguas de sinais nas universidades brasileiras, tanto em nível de graduação - com a iniciação científica e os trabalhos de conclusão de curso - quanto de pós-graduação - com as pesquisas oriundas de especializações, mestrados, doutorados e pós-doutorados, com destaque para os Programas de Pós-Graduação em Estudos da Tradução da UFSC - PGET - , da UnB - POSTRAD - e da UFC - POET -, os quais têm, cada vez mais, incorporado professores -pesquisadores e estudantes vinculados aos ETILS. 
Além disso, grupos e núcleos de pesquisa foram criados e consolidados em várias instituições, assim como os cursos de graduação direcionados à formação de tradutores e de intérpretes de Libras-português, que ganharam espaço, principalmente, nas universidades federais (UFSC, UFRJ, UFG, UFES, UFRR, UFSCar, UFRGS e UFGD). Esse movimento formativo tem incentivado pesquisas e favorecido a difusão dos ETILS nas instituições de ensino superior, assim como potencializado a interlocução entre os professores-pesquisadores dos ETILS, nacional e internacionalmente, em prol do aperfeiçoamento da formação de profissionais e de pesquisadores da tradução, da interpretação e da guia-interpretação de/entre/para línguas de sinais.

É importante mencionar também que outros volumes especiais ou Dossiês específicos foram publicados, posteriormente, marcando o avanço dos ETILS, dentre os quais podemos citar: (1) "Estudos da Tradução e Interpretação de Línguas de Sinais”, v. 35 n. 2, da Cadernos de Tradução da UFSC, publicado em 2015, organizado por Carlos Henrique Rodrigues e Ronice Müller de Quadros; (2) "Tradução e Interpretação das Línguas de Sinais", v. 5 n. 1, publicado pela Belas Infiéis da UnB, em 2016, e organizado porr \José Ednilson Gomes de Souza Junior; (3) "Tradução e Interpretação de Línguas de Sinais", v. 15, publicado pela Translatio da UFRGS, em 2018, e organizado por Tiago Coimbra Nogueira e Maria Cristina Pires Pereira; (4) "Estudos da Tradução e Interpretação de Línguas de Sinais: caminhos trilhados, percursos em andamento e projeções futuras?", v. 8, n. 1, publicado pela Belas Infiéis da UnB, em 2019, com a organização de Tiago Coimbra Nogueira e Silvana Aguiar dos Santos; e (5) "Estudos da Tradução e Interpretação de Línguas de Sinais: questões contemporâneas”, n. 51, publicado pela Revista Espaço do INES, em 2020, e organizado por Silvana Aguiar dos Santos e Guilherme Lourenço.

Todas essas publicações evidenciam a consolidação e o crescimento dos ETILS no Brasil e, assim como o volume publicado em 2010, passam a "fazer parte desse movimento que representa um avanço para as pesquisas em tradução e interpretação de lín- 
guas de sinais, bem como redefinem a formação dos profissionais desta área no país" (Palavras de Ronice Quadros na Apresentação de "Tradução e Interpretação de Línguas de Sinais", v. 2, n. 26). $\mathrm{E}$, como uma das forças atuantes nesse movimento em prol dos ETILS, a Cadernos de Tradução, uma vez mais, assume seu pioneirismo ao publicar esse volume especial: "Estudos da Tradução e da Interpretação de Línguas de Sinais: atualidades, perspectivas e desafios" com todos os artigos tendo uma versão escrita e outra em Libras em vídeo (i.e., uma abridged version/ tradução sintética).

Este volume especial, organizado pelos professores-pesquisadores brasileiros da Universidade Federal de Santa Catarina, Carlos Henrique Rodrigues e Rodrigo Custódio da Silva, e pela professora-pesquisadora catalã da Universitat Autònoma de Barcelona (UAB), Anabel Galán-Mañas, é composto por onze artigos escritos por vinte e um autores pertencentes a onze diferentes instituições, a saber: UFSC, UFMG, UFG, UnB, UFSCar, PUC-SP, UFRGS, IFCE, UFMA, UFES e UFOP.

As temáticas são diversas, envolvendo: crítica de tradução; competência tradutória; interpretação educacional; interpretação de conferências; tradução e interpretação audiovisual; mercado de trabalho; tradução literária; tradução intramodal gestual-visual; formação; tradução/revisão de textos escritos por pessoas surdas; entre outras.

As pesquisas apresentadas contam com diferentes abordagens teóricas e metodológicas, valendo-se de estudo bibliográfico, observação, revisão sistemática, aplicação de questionários, estudo empírico-experimental, análise reflexiva, grupo focal, estudo bibliométrico, entrevista semiestruturada, estudo de caso, interação on-line, estudo de recepção etc. A diversidade de pontos de vista e a multiplicidade das reflexões apresentadas trazem à tona temas atuais dos Estudos da Tradução e dos Estudos da Interpretação, destacam seus desafios contemporâneos e contribuem para o surgimento de novos interesses de investigação, corroborando as perspectivas trans/inter/multidisciplinares dos ETILS. Some-se aos artigos, uma resenha do livro: Interpreting in Legal Settings, um 
clássico organizado por Debra Russell (Universidade de Alberta) e Sandra Hale (Universidade de Nova Gales do Sul) e uma tradução para o português de um importante texto dos Estudos da Tradução.

O primeiro artigo, escrito por Ricardo Oliveira Barros (UFSC) e Marlova Aseff (UnB), intitulado "O Pequeno Príncipe em Libras: uma proposta de crítica de tradução”, apresenta uma discussão acerca das dificuldades e possibilidades de se construir a crítica da tradução da versão em Libras de $O$ Pequeno Príncipe, a qual foi produzida no âmbito do projeto Acessibilidade em Bibliotecas Públicas (ABP) do governo federal brasileiro. Os professores-pesquisadores pontuam possíveis critérios a serem seguidos na construção da crítica de uma tradução para a língua de sinais, listando certas dificuldades atreladas a esse processo. Para tanto, os autores adotam a perspectiva de análise reflexiva de Berman para a realização da análise da tradução em foco em relação ao texto de partida em português. Assim, refletem sobre o processo de construção da crítica em si, observando as dificuldades inerentes à sua construção, quando a obra é em Libras, assim como os possíveis parâmetros que poderiam orientar a análise da obra e a construção da crítica. Como conclusão, os autores destacam as dificuldades do crítico em relação ao registro da obra em vídeo e ao fato de o sistema literário da Libras ainda ser embrionário e afirmam a importância de se considerar a maneira como as traduções se alocam frente às demais obras em Libras, no que se refere à consolidação desse polissistema literário como um campo de pesquisa.

No segundo artigo, "Estudo Exploratório da Competência Tradutória de Tradutores Ouvintes Intermodais em Relação à sua Prática", Eduardo Andrade Gomes (UFMG) e Thaís Fleury Avelar (UFG), considerando que os componentes da competência tradutória podem ser impactados a partir de aspectos como a direcionalidade do processo, o tipo e o gênero textual e as modalidades (de uso) das línguas envolvidas, apresentam resultados de uma pesquisa exploratória realizada com oito tradutores ouvintes, das regiões Sudeste e Sul do país. Para coletar os dados, os pesquisadores realizaram uma entrevista semiestruturada com 
questões referentes à prática tradutória. Segundo eles, os dados demonstram que, apesar de esses tradutores preferirem atuar na direção inversa, ou seja, do português escrito para a Libras oral, a manifestação corporal, gestual e visual e o uso do espaço são considerados desafiadores, principalmente por envolver o registro em vídeo da tradução. Como conclusão, os autores ressaltam a importância de se considerar a especificidade de uma competência tradutória intermodal de modo a oferecer aos tradutores a possibilidade de acessarem formações que englobem atividades nas duas direções - direta e inversa - emprego de ferramentas de busca e maior variedade de textos, entre outros.

O próximo artigo, "Indicadores Bibliométricos da Produção Acadêmica Internacional Sobre o Intérprete Educacional de Línguas de Sinais", das pesquisadoras Neiva de Aquino Albres (UFSC) e Mairla Pereira Pires Costa (UFSC), apresenta um estudo bibliométrico das produções acerca da interpretação educacional de/para Línguas de Sinais. As pesquisadoras consideram que a produção científica é uma rica fonte para compreender o desenvolvimento de determinada área e seus desdobramentos e, por sua vez, serve para mapear a dinâmica de dado objeto de investigação em inter-relação com aspectos sociais, culturais e históricos. A partir desse pressuposto, e com base na perspectiva da arquitetônica bakhtiniana, revisitam-se algumas pesquisas anteriores que registram levantamentos de produções científicas acerca da interpretação educacional envolvendo línguas de sinais; identificam-se as distribuições espaço-temporais, sintetizando os respectivos temas específicos; e mapeia-se o desenvolvimento do campo da Interpretação Educacional de Línguas de Sinais nas três últimas décadas. As pesquisadoras analisam, também, cinco periódicos científicos internacionais sobre Educação de Surdos e sobre Linguística das Línguas de Sinais. Como resultados, listam 38 artigos e os temas de mais destaque: interpretação em sala de aula; inclusão escolar e formação de intérprete educacional. Nas considerações, as autoras alertam para o fato de que alguns temas têm sido pouco abordados - como saúde ocupacional, as competências para interpretar, os 
aspectos linguísticos e culturais relacionados à interpretação -, os quais, atualmente, demandam atenção e investigação.

No quarto artigo, "O Intérprete de Libras no Contexto da PósGraduação: um olhar para o gênero do discurso”, Vânia de Aquino Albres Santiago (PUC-SP) e Cristina Broglia Feitosa de Lacerda (UFSCar), analisam a interpretação de línguas de sinais na esfera educacional, no contexto da pós-graduação lato sensu, em relação aos gêneros discursivos com os quais os intérpretes educacionais precisam lidar. Fundamentadas no pensamento bakhtiniano e do Círculo e nas reflexões e estudos sobre o intérprete educacional, as pesquisadoras refletem sobre as estratégias empregadas pelos intérpretes nesse contexto e demonstram que a atuação de intérpretes educacionais é regida pelas coerções do gênero e, portanto, as decisões tradutórias, o estilo de linguagem, as modalidades de interpretação e as formas de interação são dependentes do contexto específico em que esses profissionais atuam.

No artigo, "Interpretação de Conferências: percepção de intérpretes de Libras-português sobre a atuação em cabine", Tiago Coimbra Nogueira (UFRGS) reflete sobre os aspectos que caracterizam a interpretação de línguas de sinais realizada na cabine em contexto de conferência. Para tanto, o pesquisador apresenta algumas situações históricas de interpretação em cabine, assim como alguns de seus personagens. Em continuidade, aborda a interpretação em cabine realizada por intérpretes de línguas de sinais, descrevendo as características dessa atuação e analisando suas vantagens, seus problemas e seus desafios. O autor destaca que abordar essa atividade, ainda pouco comum para os intérpretes de línguas de sinais, no contexto brasileiro, oferece subsídios para intérpretes e contratantes, gerando novas reflexões sobre as formas de aperfeiçoar a compreensão do serviço prestado e de favorecer sua qualidade.

Vinícius Nascimento (UFSCar), no sexto artigo, denominado “Tradução e interpretação audiovisual da língua de sinais (TIALS) no Brasil: um estudo de recepção sobre as janelas de Libras na comunidade surda", compartilha os resultados de uma pesquisa de amplitude nacional que objetivou compreender a preferência dos 
surdos em relação às janelas de Libras, que constituem o espaço de circulação da tradução e interpretação da língua de sinais em obras audiovisuais. $\mathrm{O}$ pesquisador coletou dados por meio da aplicação de um questionário virtual bilíngue que apresentava cinco propostas de janelas para três gêneros do audiovisual: cinematográficocomédia, jornalístico-televisivo e videoaula. Os dados mostram que a preferência pelas janelas se altera de acordo com o gênero avaliado e indicam que há a necessidade de se debater as proposições e inserções dessas janelas a partir dos gêneros discursivos, afastando-se de uma imposição normativa estanque. Além disso, o autor destaca a necessidade de mais estudos de recepção junto à comunidade surda brasileira, no que se refere aos produtos da tradução audiovisual.

Em "Mercado de Trabalho de Intérpretes e Tradutores de Língua Brasileira de Sinais e Língua Portuguesa: identidade e profissionalização", Renata Cristina Vilaça Cruz (UFG) constrói uma análise do mercado de trabalho de intérpretes e tradutores de Libras-português. Com o propósito de descrever este mercado - a partir das seguintes perspectivas: contextos de atuação, jornada de trabalho, remuneração, trabalho voluntário, valorização e descrição das atividades desenvolvidas - , a pesquisadora investigou, por meio de um questionário e de um grupo focal, dezoito intérpretes e tradutores que trabalham no interior do estado de Minas Gerais. Os resultados indicam que os profissionais atuam em diferentes contextos, predominantemente, em interpretação educacional; e apontam a longa jornada de trabalho, o exercício de funções que ultrapassam as atividades de interpretação e de tradução; e a busca pela valorização da profissão, bem como a ruptura com a visão assistencialista. A autora conclui que se fazem necessárias novas políticas de valorização e de conscientização acerca da profissão de intérprete e de tradutor de Libras-português no Brasil.

Em "Literatura Surda: análise de um conto infantil à luz da tradução intercultural e intermodal”, oitavo artigo que compõe este volume, Lyvia de Araújo Cruz (IFCE), Michelle Arrais Guedes (IFCE) e Andréa Michiles Lemos (IFCE) problematizam a Lite- 
ratura Surda em sua interface com os Estudos da Tradução e com os Estudos Culturais. Para tanto, as pesquisadoras realizam uma análise da tradução do conto literário "O sanduíche da Maricota" de Avelino Guedes, escrito em português, para a Libras em vídeo, contrastando-a com uma proposta tradutória que considera as estratégias de tradução intermodal e intercultural. As autoras destacam a necessidade de mais pesquisas e, portanto, de discussões acerca da tradução literária para a Libras, as quais são indispensáveis à constituição e ao aperfeiçoamento de estratégias, conhecimentos e orientações referentes ao processo de tradução literária para Libras, direcionada ao público surdo sinalizante.

No nono artigo, escrito em inglês por Arenilson Costa Ribeiro (UFMA) e Rachel Louise Sutton-Spence (UFSC), intitulado "Ball, Stone, Ball: Interlingual, Intramodal And Intersemiotic Translation Between And From A Work Of Creative Sign Language", temos uma análise de traduções de uma narrativa poética da Língua de Sinais Americana (ASL) para um relato humorístico em Libras e, por fim, da Libras para um teatro dramatizado. Os pesquisadores abordam um campo praticamente inexplorado: o das traduções intramodais gestuais-visuais, ou seja, aquele que se dá entre línguas de sinais. Assim, eles apresentam a análise da tradução do poema narrativo "Ball Story", em ASL, de Ben Bahan para um texto humorístico em Libras, realizada por Sandro Pereira, e, em seguida, para uma adaptação teatral visual feita por alunos de graduação, estudantes de literatura de língua de sinais. Os autores destacam que, apesar de algumas pequenas diferenças, o mesmo conteúdo foi apresentado nas traduções para os diferentes gêneros, sendo a versão poética mais performática em termos de declamação, a versão humorística mais focada na manipulação de parâmetros dos sinais, incorporação e intensidade e a tradução dramatizada direcionada aos aspectos cinemáticos, que se baseiam na Libras, mas não fazem uso dela. Por fim, a reflexão apresentada contribui com o estudo da tradução gestualvisual de literatura, ampliando a compreensão da estrutura de textos criativos em línguas de sinais e suas possíveis traduções. 
Cassio Pereira Oliveira (UFES) e Lucyenne Matos da Costa Vieira-Machado (UFES), em "Como Se Chega a Ser o Que Se é: formação-experiência como atitude despossível na produção de subjetividades TILSP", décimo artigo que compõem esse volume, analisam e problematizam como, no processo formativo, vêm sendo constituídas as tecnologias de modulação nas condutas dos Tradutores e Intérpretes de Libras-português. Os pesquisadores abordam a formação por meio de uma perspectiva ética e estética, considerando os processos de sujeição, bem como as linhas de fugas que produzem subjetividades específicas. Para tanto, utilizam o registro de conversas realizadas on-line, durante o contexto de isolamento social imposto pela pandemia mundial, com 122 tradutores e intérpretes de Libras-português de todos as regiões do Brasil, as quais são analisadas com base em quatro figuras subjetivas, a saber: TILSP endividado, mediatizado, securitizado e representado. $\mathrm{Na}$ reflexão apresentada, a figura do TILSP securitizado é usada para problematizar e decompor o conceito de formação e nas vozes ecoadas nas conversas com os diferentes TILSP dos diferentes espaços/lugares a formação-experiência. Os autores entendem que existe um caminhar em direção ao encontro das diferentes singularidades, produzindo, assim, sujeitos-potências capazes de rebelarse e produzirem-se em figuras de poder a partir de subjetividades outras não nomeadas.

No último artigo que integra o volume, denominado "Uma Reflexão Inicial sobre o Processo de Tradução/Revisão de um Texto Produzido por uma pessoa Surda em Português Escrito", de autoria de Christianne Câmara Lopes Albuquerque Miranda (UFOP), José Luiz Vila Real Gonçalves (UFOP) e Carlos Henrique Rodrigues (UFSC), discute-se o processo de tradução/revisão de textos de pessoas surdas, os quais são produzidos em português escrito como segunda língua. O interesse dos pesquisadores foi contrastar esse processo singular conduzido, de um lado, por profissionais tradutores e intérpretes de Libras-português e, por outro, por revisores de português que não dominam a Libras. Para tanto, utilizaram-se dados de rastreamento ocular coletados em um estudo experimen- 
tal-exploratório conduzido com esses dois grupos. Na discussão e análise dos dados, verificou-se qual grupo de profissionais despende maior esforço cognitivo, refletindo-se sobre as características da atividade e suas possíveis implicações para o profissional que a executa. Como conclusão, os autores destacam que a atividade, ao ser desempenhada pelos tradutores e intérpretes ou pelos revisores, assume uma natureza distinta e, por sua vez, implica demandas cognitivas e comportamentais diferentes.

Como se pode observar, este volume, terceiro da Cadernos de Tradução inteiramente dedicado à tradução e à interpretação de/ entre/para línguas de sinais, representa o crescimento, a consolidação e o amadurecimento das pesquisas dos ETILS e marca um novo tempo da investigação da tradução, da interpretação e da guia -interpretação intermodal e intramodal gestual-visual no contexto brasileiro. Seu desenvolvimento resulta da parceria UFSC-UAB, proporcionada pelo projeto "Tradução, Tradição e Inovação", que faz parte das perspectivas de internacionalização incentivadas pela Coordenação de Aperfeiçoamento de Pessoal de Nível Superior no âmbito do Programa Institucional de Internacionalização, CAPES -PrInt, congregando, como organizadores, dois professores-pesquisadores brasileiros da UFSC e uma professora-pesquisadora catalã da Universitat Autònoma de Barcelona (UAB). Esperamos que a leitura de cada um dos artigos, que compõem essa obra, contribua com o melhor conhecimento da área e com sua difusão, fomentando novas questões de pesquisa e incentivando à sua divulgação, inclusive, em línguas de sinais.

Carlos Henrique Rodrigues

Universidade Federal de Santa Catarina, Florianópolis, Santa Catarina, Brasil

Anabel Galán-Mañas

Universitat Autònoma de Barcelona, Barcelona, Catalunya, Espanya

Rodrigo Custódio da Silva

Universidade Federal de Santa Catarina, Florianópolis, Santa Catarina, Brasil

Cad. Trad., Florianópolis, v. 41, $\mathrm{n}^{0}$ esp. 2, p. 09-18, ago/dez, 2021. 